\section{From the authors:}

We would like to thank T.L. Petty for his interesting comments regarding our trial of ambulatory oxygen (AO) in chronic obstructive pulmonary disease (COPD) [1]. The question raised by T.L. Petty was the following: when is the best time to initiate $\mathrm{AO}$ in oxygen-dependent COPD? He suggested AO should be provided as early as possible after the introduction of long-term oxygen therapy (LTOT) to avoid rapid adjustment to the limitations imposed by the stationary oxygen delivery system.

Unfortunately, inappropriate prescription of LTOT is not unusual [2]. Our trial strictly targeted oxygen-dependent patients. Thus, to be included, patients had to be on LTOT for $\geqslant 3$ months. This was to avoid the inclusion of patients who were prescribed oxygen following an acute exacerbation of the disease and who may not fulfil LTOT criteria upon reevaluation. Therefore, at study entry, our patients were not oxygen naive.

The problem is that oxygen dependence cannot be easily confirmed in oxygen-naive patients. In our experience, acute exacerbation precedes the prescription of LTOT in most patients, i.e. during a period of clinical instability. In addition, $\geqslant 30 \%$ of patients meeting criteria for domiciliary oxygen after 1 month of apparent stability no longer met the same criteria after an additional 3 months of observation [3]. Whether provision of $\mathrm{AO}$ to oxygen-dependent patients would have an effect on quality of life if it was introduced earlier would pose important, methodological problems to clinical trials.
In conclusion, we would rather ask the following question: what is the best way of initiating ambulatory oxygen in oxygen-dependent chronic obstructive pulmonary disease? In this regard, we agree with T.L. Petty that it would be of interest to evaluate whether pulmonary rehabilitation in conjunction with ambulatory oxygen could facilitate compliance and further improve quality of life.

\section{Y. Lacasse and F. Maltais}

Centre de recherche, Hôpital Laval, Institut universitaire de cardiologie et de pneumologie de l'Université Laval, Québec, Canada

\section{REFERENCES}

1 Lacasse Y, Lecours R, Pelletier C, Bégin R, Maltais F. Randomised trial of ambulatory oxygen in oxygendependent COPD. Eur Respir J 2005; 25: 1032-1038.

2 Guyatt GH, McKim DA, Austin P, et al. Appropriateness of domiciliary oxygen delivery. Chest 2000; 118: 1303-1308.

3 Levi-Valensi P, Weitzenblum E, Pedinielli JL, Racineux JL, Duwoos H. Three-month follow-up of arterial blood gas determinations in candidates for long-term oxygen therapy: a multicentric study. Am Rev Respir Dis 1986; 133: 547-551.

\title{
Randomised trial of ambulatory oxygen in oxygen-dependent COPD
}

DOI: 10.1183/09031936.05.00073305

\section{To the Editors:}

I read with interest the article by LACASSE et al. [1], which found no benefit in using ambulatory oxygen (AO) in chronic obstructive pulmonary disease. I think that there were not enough patients in the study not to recommend its use. The authors have not shown the variations of oxygen saturation during the 6-minute walking test (6MWT). Oxygen therapy may improve exercise capacity in patients with desaturation during the walking test [2].

Liquid oxygen is better than gas from cylinders for $\mathrm{AO}$ therapy. The ENRIGHT and SHERILL [3] reference values of a $6 \mathrm{MWT}$ are very different from those of TROOSTERs et al. [4] or GibBONs et al. [5]. The latter references may be preferable because the equation by ENRIGHT and SHERILL [3] gives smaller values. In my opinion, the average partial pressure of oxygen at rest of the patients, $7.0 \mathrm{kPa}(53 \mathrm{mmHg})$, was not very low. In patients with severe hypoxaemia, the results could possibly differ.

I believe that ambulatory oxygen therapy in chronic obstructive pulmonary disease should depend on each patient. A certain subgroup of patients with chronic obstructive pulmonary disease might benefit from ambulatory oxygen. The 6-minute walking test is a prognostic tool that gives a valuable insight into the normal activities of daily living.

\section{García-Talavera}

Investigation Unit, Candelaria University Hospital, Santa Cruz de Tenerife, Spain.

\section{REFERENCES}

1 Lacasse Y, Lecours R, Pelletier C, Bégin R, Maltais F. Randomised trial of ambulatory oxygen in oxygendependent COPD. Eur Respir J 2005; 25: 1031-1038.

2 Leach RM, Davidson AC, Chinn S, Twort CH, Cameron IR, Bateman NT. Portable liquid oxygen and exercise ability in severe respiratory disability. Thorax 1992; 47: 781-789.

3 Enrich PL, Sherill DL. Reference equations for the six minutes walk in healthy adults. Am J Respir Crit Care Med 1998; 158: 1384-1387. 